\title{
Research Article
}

\section{A comparison of pre-operative and post-operative use of 10\% lignocaine aerosol for post-tonsillectomy pain relief in paediatric patients}

\author{
Bhavesh K. Dalwadi $^{1}$, Jigna B. Dalwadi ${ }^{2}$
}

\author{
${ }^{1}$ Department of Anaesthesia, GMERS Medical College, Gotri, Vadodara, Gujarat, India \\ ${ }^{2}$ Anaesthesiologist, Jamanabai Hospital, Mandvi, Vadodara, Gujarat, India
}

Received: 21 September 2015

Revised: 15 October 2015

Accepted: 25 October 2015

\author{
*Correspondence: \\ Dr. Bhavesh K. Dalwadi, \\ E-mail: bhaveshkdalwadi@gmail.com
}

Copyright: () the author(s), publisher and licensee Medip Academy. This is an open-access article distributed under the terms of the Creative Commons Attribution Non-Commercial License, which permits unrestricted non-commercial use, distribution, and reproduction in any medium, provided the original work is properly cited.

\begin{abstract}
Background: Tonsillectomy surgery is most commonly carried out in paediatric age group. Pain relief after tonsillectomy in children remains a dilemma for anaesthesia. Rapid recovery from anaesthesia and return of protective relflexes are desirable earliest. There are conventional methods for pain relief post-tonsillectomy but use of local anaesthetic agents provide pain relief without any adverse effect. Hence we carried out our study in 4-12 years of age group and compare efficacy of pre-operative and post-operative $10 \%$ lignocaine aerosol for post-tonsillectomy pain relief.

Methods: After institutional approval and informed consent 75 ASA I AND II children in 4-12 years of age group undergoing tonsillectomy were taken. In group A children did not receive any local anaesthetic whereas in group B children received $10 \%$ lignocaine aerosol pre-operative 3 minutes prior tonsillectomy and group $\mathrm{C}$ children received post-tonsillectomy aerosol in tonsillar fossa raw area. Anaesthetic management was standardized. Post-operative pain assessment done via behavioural scale.

Results: The mean age, weight and duration of surgeries were not significantly different when compared in all three groups. In both study group B and C duration of analgesia is comparable in postoperative period. In both group no analgesia required upto 3 hours after surgery. In group C recovery was delayed compared to group B.

Conclusions: The use of $10 \%$ lignocaine aerosol is easy, safe and effective method for post-tonsillectomy pain relief in paediatrics.
\end{abstract}

Keywords: $10 \%$ lignocaine aerosol, Post-tonsillectomy pain, Paediatric age group

\section{INTRODUCTION}

Pain is an unpleasant sensory and emotional experience dut to tissue damage. Post-operative pain relief is an important and inevitable part of anaesthesia. In past postoperative pain relief was neglected in paediatric patients because of misconceptions as children don't feel much pain and don't remember as adults.
It is proven that significant psychological trauma and sufferings with fear and apprehension can occur in children due to surgical pain. Painful and distressed recovery would cause a great impact on child psyche and delay the early discharge.

As tonsillectomy is most commonly carried out in children it is many a time first surgical exposure for otherwise healthy child. Pain relief post-tonsillectomy in children remains a dilemma for anaesthetists. Rapid 
recovery from anaesthesia and return of protective reflexes is desirable earlier. Inadequate analgesia can delay smooth emergence and speedy recovery. ${ }^{1}$ Pain can lead to poor oral intake post-operatively which sometimes force clinician for overnight hospitalization of patient.

Conventional methods by variety of medications have been tried including NSAIDS and narcotics in paediatrics for post-tonsillectomy pain relief. Various routes including intramuscular, intravenous, rectal, oral and topical have been used for analgesic drugs. Various narcotic agents like codeine, pethidine and pentazocine have been used to provide efficient analgesia. NSAIDS like diclofenec can be given oral, rectal, intramuscular or intravenous by infusion.

Studies to relieve pain and infection have been done by Mr. Joel Smith (1960) and colleagues who injected a suspension of penicillin, lignocaine and depo-medrol (steroid) in tonsillar fossa. He proved lignocaine to be effective analgesic but failed to explain the reason of its prolonged action. Studies ${ }^{2}$ have been conducted using pentazocine or paracetamol but found to be insufficient as extraanlgesics were needed. Post -operative intramuscular diclofenec ${ }^{3}$ offer good pain relief but very painful intramuscular injections in paediatrics are less acceptable (Smith V edition 1990). Intravenous opioids ${ }^{4}$ can cause respiratory depression and vomiting.

Local anaesthetics have advantage over other methods as they don't cause respiratory depression, PONV, delayed recovery, hemodynamic instability. Various methods using local anaesthetic agents ${ }^{5-7}$ like lignocaine as infiltration, topical and bupivacaine ${ }^{8}$ embedded gauge used for post-tonsillectomy analgesia.

We chose $10 \%$ lignocaine aerosol for post-tonsillectomy pain relief in paediatrics as it offers the advantages like ease of administration, safe with quick onset and no need of extra analgesia in post-operative period. ${ }^{9,10}$ Aerosol delieverd in form of microdroplets (5 micron size) through special nozzle fitted on the bottle.

Thus realizing the benefits of topical application of local anaesthetics in tonsillar fossa for analgesia, we did a prospective study to observe and to prove efficacy of $10 \%$ lignocaine aerosol as pre-operative and postoperative for tonsillectomy children. We used behavioural scale and self-report scales to assess the degree of pain in children. ${ }^{11}$

\section{METHODS}

The study was carried out after the approval from ethical committee and informed written consent of the parents. 75 patients between the age group of 4 to 12 years of either sex undergoing tonsillectomy were selected. All children belonged to ASA Grade-I or II. They were divided in three groups as group-A $(n=25)$ as controlled group, group B $(n=25)$ receiving pre-operative lignocaine aerosol 3 minutes prior surgery and group $C(n=25)$ received aerosol post-tonsillectomy after hemostasis.

\section{Selection of patients}

As tonsillectomy is common in paediatrics, we conducted out study in 75 ASA G-I or II children between 4 to 12 years of age group. Male to female ratio in all three groups are comparable. In our study we selected all children weighing between $10-30 \mathrm{~kg}$ range. Surgeries which took longer time because of failure to achieve hemostasis were excluded from our study.

\section{Pre-operative evaluation}

Pre-operative visit was conducted one day before surgery. Detailed history of all patients in presence of parents was taken. Weight and general examination done. Systemic examination of cardiovascular and respiratory system was done to rule out any lower respiratory infection.

\section{Pre-operative order}

Patients were advised to remain nil orally for 6 to 8 hours before surgery depending on age of the patient. Also explained about visual analogue scale.

\section{Anaesthesia}

Intravenous access secured with $22 \mathrm{G}$ i.v. cannula in all patients and inj. 5\% dextrose started. PR and BP recorded. All patients received inj. glycopylorrate (10 microgm $/ \mathrm{kg})$ i.v. inj. Pentazocine $(0.3 \mathrm{mg} / \mathrm{kg})$ with inj. promethazine $(0.25 \mathrm{mg} / \mathrm{kg})$ given i.v. as diluted solution. Pulseoxymeter and cardioscope applied for monitoring vitals. Nasal otrivin 1-2 drops put in nasal cavity. After preoxygenation general anaesthesia administered with inj. sodium pentothal $(8-10 \mathrm{mg} / \mathrm{kg})$ i.v. followed by inj. suxamethonium $(2 \mathrm{mg} / \mathrm{kg})$. After ippv nasal intubation done with plain or cuffed endotracheal tube with jelly applied for smooth passage. Inj. vecuronium $(0.08$ $\mathrm{mg} / \mathrm{kg}$ ) i.v. given for intraoperative muscle relaxation. Maintenance of anaesthesia done with $\mathrm{O}_{2}, \mathrm{~N}_{2} \mathrm{O}$ and isoflurane. Throat packed with roller gauge to prevent aspiration of blood. Tonsillar position given for surgery.

Patients allocated in group $\mathrm{B}$ and $\mathrm{C}$ received preoperative and post-operative $10 \%$ lignocaine aerosol respectively in tonsillar fossa with special nozzle fitted on bottle in dose of $4 \mathrm{mg} / \mathrm{kg}$. Group A (control group) didn't receive aerosol. Intraoperative vitals noted. At the end of surgery, reversal with inj. Neostigmine $(0.05 \mathrm{mg} / \mathrm{kg})$ with inj. atropine $(0.02 \mathrm{mg} / \mathrm{kg})$ i.v. given and extubation done when patient fully awake. Left lateral position given to prevent accidental aspiration.

In post-operative period all patients monitored for pulse rate, blood pressure and respiratory rate. Time of awakening from anaesthesia noted. All patients are 
monitored with behavioural scale and visual analogue score (0 - no pain to 10 - worst pain) at the end of 5, 30, 60 minutes and 2, 3, 4 hours.

\section{Statistical analysis}

The data obtained in present study was expressed as mean \pm standard deviation. The data were analyzed by ' $\mathrm{z}$ test'. The level of significance was taken as $\mathrm{p}<0.05$.

\section{RESULTS}

A clinical study was undertaken to study pre-operative (group B) and post-operative (group C) use of $10 \%$ lignocaine aerosol in 4 to 12 years of paediatric patients for post-tonsillectomy pain relief. Group A constitutes control group. Each group has 25 children.

Table 1 shows age distribution in all 3 groups are comparable (4-12 years of age group). Also in all 3 groups weight and ASA grade I-II distribution are comparable.

Table 1: The distribution of patients according to age in all 3 groups (4-12 years); $N=25$ each.

\begin{tabular}{|lllllll|}
\hline \multirow{2}{*}{ Age (years) } & \multicolumn{2}{l}{ Group A } & \multicolumn{2}{c|}{ Group B } & \multicolumn{2}{c|}{ Group C } \\
\cline { 2 - 8 } & No. & $\mathbf{\%}$ & No. & $\mathbf{\%}$ & No. & \% \\
\hline $5-7$ & 10 & 40 & 12 & 48 & 9 & 36 \\
\hline $8-10$ & 9 & 36 & 10 & 40 & 6 & 24 \\
\hline $11-12$ & 6 & 24 & 3 & 12 & 10 & 40 \\
\hline Total & 25 & 100 & 25 & 100 & 25 & 100 \\
\hline Mean \pm SD & $8.36 \pm 2.27$ & $7.88 \pm 1.99$ & $8.8 \pm 2.48$ \\
\hline
\end{tabular}

Majority of patients in all 3 groups have their basal pulse rate in range of $90-100 / \mathrm{min}$.

Table 2: Weight distribution among all 3 groups; $\mathrm{N}=25$ each.

\begin{tabular}{|lllllll|}
\hline \multirow{2}{*}{ Weight (kg) } & \multicolumn{2}{c}{ Group A } & \multicolumn{2}{c|}{ Group B } & \multicolumn{2}{c|}{ Group C } \\
\cline { 2 - 8 } & No. & \% & No. & \% & No. & \% \\
\hline$\leq 20$ & 12 & 48 & 10 & 40 & 13 & 52 \\
\hline$>20$ & 13 & 52 & 15 & 60 & 12 & 48 \\
\hline Total & 25 & 100 & 25 & 100 & 25 & 100 \\
\hline Mean \pm SD & $18.8 \pm 4.53$ & $18.76 \pm 4.53$ & $19.84 \pm 4.04$ \\
\hline
\end{tabular}

Table 3 shows that there is significant increase in pulse rate in group A (control) in post-operative period compared to their basal pulse rate. Whereas in group B and $\mathrm{C}$, no significant rise of pulse rate after surgery.

As this Table 3 shows the change in the pulse rate between pre-operative and post-operative period. In control group A $24 \%$ of patients have increase in pulse rate $>10 /$ min, which is highly significant rise.
Table 3: Change in pulse rate between post-op to preop in all 3 groups, $(\mathrm{N}=25)$.

\begin{tabular}{|c|c|c|c|c|c|c|}
\hline \multirow{2}{*}{$\begin{array}{l}\text { Change in } \\
\text { pulse rate }\end{array}$} & \multicolumn{2}{|c|}{ Group A } & \multicolumn{2}{|c|}{ Group B } & \multicolumn{2}{|c|}{ Group C } \\
\hline & No. & $\%$ & No. & $\%$ & No. & $\%$ \\
\hline$>+10$ & 6 & 24 & 1 & 4 & 2 & 8 \\
\hline$+6-10$ & 2 & 8 & 3 & 12 & 4 & 16 \\
\hline$+1-5$ & 12 & 48 & 10 & 40 & 9 & 36 \\
\hline No change & 5 & 20 & 6 & 24 & 7 & 28 \\
\hline$(-1)-(-5)$ & 0 & 0 & 3 & 12 & 1 & 4 \\
\hline$(-6)-(-10)$ & 0 & 0 & 2 & 8 & 1 & 4 \\
\hline$>-10$ & 0 & 0 & 0 & 0 & 1 & 4 \\
\hline Total & 25 & 100 & 25 & 100 & 25 & 100 \\
\hline$p$ value & \multicolumn{2}{|c|}{$\begin{array}{l}\text { Highly } \\
\text { significant } \\
\text { P:0.001 }\end{array}$} & \multicolumn{2}{|c|}{$\begin{array}{l}\text { Non- } \\
\text { significant }\end{array}$} & \multicolumn{2}{|c|}{$\begin{array}{l}\text { Non- } \\
\text { significant }\end{array}$} \\
\hline
\end{tabular}

Time of awakening compared between three groups which suggest as shown in Table 4, there is significant delayed in awakening in group $\mathrm{C}$ (post op).

Table 4: Time of awakening in all three groups; $\mathrm{N}=25$ each.

\begin{tabular}{|llll|}
\hline Time & Group A & Group B & Group C \\
\hline $\begin{array}{l}\text { Mean values } \\
\text { (minutes) }\end{array}$ & 6.07 & 6.12 & 12.15 \\
\hline
\end{tabular}

Above Table 4 shows the average time of awakening post-operatively in all the three groups. In group $\mathrm{C}$, time of awakening compared to group A and group B, is significantly delayed (' $p$ ' value $<0.01$ ).

In early post-operative period in control group $\mathrm{A}$, there is significant pain and discomfort compared to group B and $\mathrm{C}$ as in both these groups most patients were asleep and calm. In group $C$ patients were significantly asleep and calm for prolonged period compared to group A.

Analysis of visual analogue score compared in all three groups. No extra analgesia needed in group B and group C for 3.5-4 hours.

Table 5: Visual analogue score (mean value with range in bracket); $\mathrm{N}=25$ each.

\begin{tabular}{|lllllll|}
\hline Group & $\mathbf{5}$ & $\mathbf{3 0}$ & $\mathbf{1}$ & $\mathbf{2}$ & $\mathbf{3}$ & $\mathbf{4}$ \\
\hline Control A & 2.9 & 2.9 & 3.8 & 4.4 & 4.6 & 3.6 \\
& $(2-6)$ & $(2-6)$ & $(2-6)$ & $(4-6)$ & $(3-6)$ & $(2-4)$ \\
\hline Pre-operative & 0.6 & 0.8 & 2.0 & 2.3 & 2.64 & 2.8 \\
lignocaine-B & $(0-2)$ & $(0-2)$ & $(0-2)$ & $(2-4)$ & $(2-4)$ & $(2-4)$ \\
\hline Post-operative & 0.5 & 0.9 & 1.6 & 2.2 & 2.52 & 3.2 \\
lignocaine-C & $(0-2)$ & $(0-2)$ & $(0-2)$ & $(2-4)$ & $(2-4)$ & $(2-4)$ \\
\hline
\end{tabular}


Table 6: Group A: behavioural score, $(\mathrm{N}=25)$.

\begin{tabular}{|lllll|} 
Time & $\begin{array}{l}\text { Asleep } \\
\text { and calm }\end{array}$ & $\begin{array}{l}\text { Asleep } \\
\text { and } \\
\text { restless }\end{array}$ & $\begin{array}{l}\text { Awake } \\
\text { and calm }\end{array}$ & $\begin{array}{l}\text { Awake } \\
\text { and } \\
\text { restless }\end{array}$ \\
\hline 5 min & $20(80 \%)$ & - & - & $5(20 \%)$ \\
\hline 0.5 hour & $16(64 \%)$ & - & - & $9(36 \%)$ \\
\hline 1 hour & $1(4 \%)$ & $9(36 \%)$ & $7(28 \%)$ & $8(32 \%)$ \\
\hline 2 hour & $1(4 \%)$ & $1(4 \%)$ & $5(20 \%)$ & $18(72 \%)$ \\
\hline 3 hour & $1(4 \%)$ & $1(4 \%)$ & $3(12 \%)$ & $20(80 \%)$ \\
\hline 4 hour & $1(5 \%)$ & - & $11(44 \%)$ & $13(52 \%)$ \\
\hline
\end{tabular}

Table 7: Group B: behavioural score, $(\mathrm{N}=25)$.

\begin{tabular}{|lllll|}
\hline Time & $\begin{array}{l}\text { Asleep } \\
\text { and calm }\end{array}$ & $\begin{array}{l}\text { Asleep } \\
\text { and } \\
\text { restless }\end{array}$ & $\begin{array}{l}\text { Awake } \\
\text { and calm }\end{array}$ & $\begin{array}{l}\text { Awake } \\
\text { and } \\
\text { restless }\end{array}$ \\
\hline 5 min & $22(88 \%)$ & - & $3(12 \%)$ & - \\
\hline 0.5 hour & $21(84 \%)$ & - & $4(16 \%)$ & - \\
\hline 1 hour & $1(4 \%)$ & $1(4 \%)$ & $20(80 \%)$ & $3(12 \%)$ \\
\hline 2 hour & - & - & $22(88 \%)$ & $3(12 \%)$ \\
\hline 3 hour & - & - & $21(84 \%)$ & $4(16 \%)$ \\
\hline 4 hour & - & - & $20(80 \%)$ & $5(20 \%)$ \\
\hline
\end{tabular}

Table 8: Group C: behavioural score, $(\mathrm{N}=25)$.

\begin{tabular}{|lllll|}
\hline Time & $\begin{array}{l}\text { Asleep and } \\
\text { calm }\end{array}$ & $\begin{array}{l}\text { Asleep } \\
\text { and } \\
\text { restless }\end{array}$ & $\begin{array}{l}\text { Awake } \\
\text { and calm }\end{array}$ & $\begin{array}{l}\text { Awake } \\
\text { and } \\
\text { restless }\end{array}$ \\
\hline 5 min & $25(100 \%)$ & - & - & - \\
\hline 0.5 hour & $24(96 \%)$ & - & - & $1(4 \%)$ \\
\hline 1 hour & $22(88 \%)$ & - & $1(4 \%)$ & $2(8 \%)$ \\
\hline 2 hour & $6(24 \%)$ & $5(20 \%)$ & $14(56 \%)$ & - \\
\hline 3 hour & $1(4 \%)$ & $6(24 \%)$ & $18(72 \%)$ & - \\
\hline 4 hour & - & - & $19(76 \%)$ & $6(24 \%)$ \\
\hline
\end{tabular}

\section{DISCUSSION}

Pain management after tonsillectomy in children ${ }^{12}$ remains a dilemma for the anaesthetist. Painful and distressed recovery would cause a great impact on child's psyche. ${ }^{13}$

Early post-operative pain following tonsillectomy remains an obstacle to speedy recovery and smooth emergence.

Inadequate analgesia causes poor oral intake and occasionally requires overnight hospitalization which is a hindrance in day care surgical practice.

A variety of medications (nonsteroidal anti-inflammatory agents, opioids and local anaesthetic agents) have been through various routs like intramuscular, intravenous, oral, rectal or topical) to alleviate the post-operative pain of tonsillectomy in paediatrics. Study using intramuscular diclofenac given immediately after surgery along with supplemented doses have good post-operative pain relief and ease at swallowing; but repeated intramuscular injections more than to the pain associated with operative procedure. Thus, post-operative pain reliefs by intramuscular injections are less acceptable in paediatric age groups (Smith V edition, 1990).

Oral route is acceptable but the drawback of this route is medication cannot be given orally in immediate postoperative period. Intravenous drug administration such as opioids can cause respiratory depression. Infiltration with local anaesthetics ${ }^{14,15}$ have advantages over narcotics or non-narcotic analgesics that They do not cause systemic effects like respiratory depression, nausea, vomiting and drowsiness. Repeated painful injections are avoided.

We chose $10 \%$ lignocaine aerosol for post-tonsillectomy pain relief in paediatrics.

In our study we compare the efficacy of $10 \%$ lignocaine in pre-operative and post-operative use for posttonsillectomy pain relief as it offers the benefit of ease of administration, hemodynamic stability and safety.

In their study ${ }^{16-18}$ they proved $4 \%$ lignocaine and other studies which used $10 \%$ lignocaine spray in dose of 4 $\mathrm{mg} / \mathrm{kg}$ body weight and found serum lignocaine level well below toxic level. In our study we used $4 \mathrm{mg} / \mathrm{kg}$ dose of $10 \%$ lignocaine aerosol in tonsillar fossa in both study group $\mathrm{B}$ and $\mathrm{C}$ and no lignocaine toxicity noted in any patient. In their study, ${ }^{19,20}$ they successfully used $10 \%$ lignocaine spray which administered topically in tonsillar bed to alleviate immediate post-operative pain and discomfort in tonsillectomy patients.

In our study, the number of patients restless in control group A went on increasing from $36 \%$ at 30 minutes to $70 \%$ at 2 hours and 12 patients needed supplementary analgesics like diclofenac at 2 hours assessment. Up to $3_{1 / 2}$ to 4 hours post-operatively, no extra analgesia required in both pre-operative and post-operative study group i.e. group B and group C. In Control group A there was significant rise in post-operative pulse rate compared to pre-operative value in significant number of patients ( $24 \%$ of patients had risen in pulse rate $>10 / \mathrm{min}$ ). In both these study groups, no significant change was noted in pulse rate, blood pressure and respiratory rate.

A study ${ }^{21}$ in children ranging from 4-10 years of age groups scheduled for elective tonsillectomy concluded that $10 \%$ lignocaine he used after tonsillectomy showed delayed recovery compared to pre-operative group. All the patients were also assessed for 'time of awakening' i.e. time taken for eye opening from discontinuation of anaesthesia. The mean time of awakening in group A was 6 minutes-7 seconds, in group B was 6 minutes-13 seconds, whereas in group C was 12 minutes-15 seconds. So, time of awakening in group $\mathrm{C}$ was comparatively prolonged and was proved to be statistically significant. 
In our study both study groups group B and C, most of the patients in early post-operative period in 5 minutes and 30 minutes were asleep and calm (Group B: $88 \%$ and $84 \%$ respectively, Group C: $100 \%$ and $96 \%$ respectively) whereas in control group A, in early post-operative period 5 minutes and 30 minutes $80 \%$ and $64 \%$ patients were asleep and calm. So, 5 patients at 5 minutes and 9 patients at 30 minutes were restless in control group. At one hour, in group B patients were more awake and calm $(80 \%)$, while $88 \%$ patients in group $\mathrm{C}$ were asleep and calm. We observed that most of the patients in immediate post-operative period were calm in both study groups.

In their study ${ }^{22,23}$ they concluded the use of topical local anaesthetic is safe and free from hemodynamic stability and systemic toxicity when used in tonsillectomy for pain relief. In our study there was not a single patient in whom local anaesthetic toxicity noted.

So in our study we concluded that $10 \%$ lignocaine aerosol is safe for post-tonsillectomy pain relief in paediatric patients and also that post-operative use of the drug significantly delay the early recovery so we prefer pre-operative use of $10 \%$ lignocaine aerosol for posttonsillectomy pain relief in paediatric patients.

Funding: No funding sources

Conflict of interest: None declared

Ethical approval: The study was approved by the institutional ethics committee

\section{REFERENCES}

1. Sutters KA. Inadequate pain management and associated morbidity in children at home after tonsillectomy. Paediatr J Nurs. 1997;12(3):178-85.

2. Anae Gaffney. Comparison of paracetamol and pentazocine suppositories for pain relief after tonsillectomy. Acta Anaesthesiol Scand. 1984;15(4):512-7.

3. Nordbladh I, Ohlander B, Björkman R. Analgesia in tonsillectomy a double blind study on pre and postoperative treatment with diclofenac. Clin Otolaryngol Allied Sci. 1991;16(8):554-8.

4. Sutherland CJ, Kesthin IG. A comparison of intramuscular tenoxicam with intramuscular morphine for post-tonsillectomy pain relief in children. Paediatr Anaesth. 1998;8(4):321-4.

5. Molliex S, Haond P, Baylot D, Prades JM, Navez M, Elkhoury Z, et al. Effect of pre and postoperative tonsillar infiltration with local anaesthetics on post-operative pain after tonsillectomy. Acta Anaesthesiol Scand. 1996;40(10):7210-5.

6. Woxg AK, Bissonnette B, Braude BM, Macdonald RM, St-Louis PJ, Fear DW. Post-tonsillectomy infiltration with $1 \%$ topical sprays of lignocaine reduces immediate post-operative pain in children. Can J Anaesth. 1997;42(9):770-4.

7. Orntoff S, Longreen A, Moiniche S, Dhal JB. A comparison of pre and post-operative tonsillar infiltration with Bupivacaine on pain after tonsillectomy. A pre-emptive effect. Anaesthesia. 1994;49(2):151-4.

8. Sharifian HA, Fathololoomi MR, Bafghi AF, Naini SAS. Effect of local bupivacaine infiltration on post-tonsillectomy pain. Tanaffos. 2006;5(1):45-9.

9. Elhakim M. Comparison of per-operative topical lignocaine sprays $10 \%$ on pain after tonsillectomy. Acta Anaesthesia Scand. 1995;39(8):1032-5.

10. Sinclair R, Cassuto J, Högström S, Lindén I, Faxén A, Hedner $\mathrm{T}$, et al. Topical anaesthesia with lignocaine aerosol in the control of post-operative pain. Anaesthesiology. 1988;68(6):895-901.

11. Chaturvedi J, Vamanshankar H, Chandrashekhar S. An assessment of post-operative pain in patients undergoing tonsillectomy. Otorhinolaryngologia. 2010;60(4):239-43.

12. Gehdoo R. Post-operative pain management in paediatric patients. Indian $\mathrm{J}$ Anaesth. 2004;48(5);406-14.

13. Morton NS. Acute paediatric pain management: a practical guide. In: Morton NS, eds. A Guide. London: W.B. Saunders; 1998.

14. Broadman LM, Patel RI, Feldman BA, Sellman GL, Milmoe G, Camilon F. The effect of peritonsillar infiltration on the reduction of intra-operative blood loss and post-tonsillectomy pain in children. Laryngoscope. 1989;99:578-81.

15. Molliex S, Haond P, Baylot D, Prades JM, Navez M, Elkhoury Z, et al. Effect of pre and postoperative tonsillar infiltration with local anaesthetics on post-operative pain after tonsillectomy. Acta Anaesthesiol Scand. 1996;40(10):7210-5.

16. Pelton DA, Cooper PD. Plasma lignocaine concentrations following topical aerosol application to the trachea and bronchi. Can Anaesth Soc J. 1970;17(3):250-5.

17. Scott DB, Littlewood DG, Covino BG, Drummond GB. Plasma lignocaine concentration following endotracheal spraying with an aerosol. Br J Anaesth. 1976;48(9):899-902.

18. Sitbon P, Laffon M, Lesage V. Lignocaine plasma concentration in paediatric patient after providing airway topical anaesthesia from a calibrated device. Anaesth Analg. 1996;82(5):2003-6.

19. Seyed Abbas Hosseini Jahromi, Seyedeh Masoumeh Hosseini Valami, Sevak Hatamian. Comparison between effect of $10 \%$ lignocaine, morphine and ketamine spray on post-tonsillectomy pain in children. Anaesthesiol Pain Med. 2012;2(1):17-21.

20. Elhakim M, Abdul Salam AY, Eid A. Inclusion of pethidine in lignocaine for infiltration improves analgesia following tonsillectomy in children. Acta Anaesth Scand. 1997;41(2):214-7.

21. Melchor MR, Villafruela MA, Muñoz B, Domingo C, Ontañón M, García A, et al. Post-operative pain in tonsillectomy in general anaesthesia and local infiltration. Acta Otolaryngol Esp. 1994;45(5):34955. 
22. Scott DB, Littlewood DG, Covino BG, Drummond GB. Plasma lignocaine concentration following endotracheal spraying with an aerosol. Br J Anaesth. 1976;48(9):899-902.

23. Whittel HB, Hayward AW, Battersby E. Plasma lignocaine levels during paediatric endoscopy of the upper respiratory tract. Anaesthesia. 1988;43(6):439-42.

Cite this article as: Dalwadi BK, Dalwadi JB. A comparison of pre-operative and post-operative use of $10 \%$ lignocaine aerosol for post-tonsillectomy pain relief in paediatric patients. Int J Res Med Sci 2015;3:3074-9. 